\title{
O que dizem jovens do Ensino Médio sobre homossexualidades mostradas no Pânico na Band?
}

\author{
Aline Maria Ülrich Bloedow ${ }^{l}$ \\ Bianca Salazar Guizzo ${ }^{2}$
}

Resumo: A escola contemporânea vem, paulatinamente, abordando temáticas que eram praticamente banidas dela há alguns anos, como a homossexualidade. O presente estudo analisa falas de jovens vinculados ao Ensino Médio, registradas durante encontros de discussão na escola, sobre representações de gênero e sexualidade, as quais foram veiculadas em certos quadros do programa Pânico na Band. Alguns resultados apontaram que a heteronormatividade aparece nas opiniões dos jovens, porém há uma crítica por parte deles no que diz respeito ao modo como a homossexualidade é apresentada no referido programa. Além disso, a transversalidade dada à educação sexual não tem formado jovens preparados para valorizar as múltiplas identidades e reconhecer as diferenças.

Palavras-chave: juventudes, ensino médio, homofobia

What do young high school students say about the homosexualities shown on Pânico na Band?

\begin{abstract}
Contemporary schools have gradually been addressing issues that were virtually banned a few years ago, such as homosexuality. This study analyzes discourses of high school students, recorded during discussion meetings at school, on gender and sexuality representations, which were broadcast in specific Panico na Band sketches. Some results show that heteronormativity is present in students' views, although criticism comes from them in regard to how homosexuality is presented in the program. In addition, cross-curricular sex education has not prepared teenagers to value multiple identities and to recognize differences. Keywords: Youth; High School; Homophobia.
\end{abstract}

\section{O QUE DIZEM JOVENS DO ENSINO MÉDIO SOBRE HOMOSSEXUALIDADES?}

No Brasil, especialmente a partir da década de 1990, alguns documentos oficiais legais passaram a ser pensados e produzidos a fim de dar visibilidade a questões que até então não eram consideradas como próprias para serem

\footnotetext{
${ }^{1}$ Mestre em Educação pela Universidade Luterana do Brasil. Especialista em Psicopedagogia Institucional pela Universidade Cidade de São Paulo. Professora na Educação Básica nas áreas de Língua Portuguesa e Literatura.

${ }_{2}$ Mestre e Doutora em Educação pela Universidade Federal do Rio Grande do Sul. Professora de graduação e pós-graduação na Universidade Luterana do Brasil.
}

\begin{tabular}{|l|l|l|l|l|} 
Textura & Canoas & v. 19 n.40 & p.210-236 & maio/ago. 2017 \\
\hline
\end{tabular}


abordadas nas escolas, em especial, com jovens escolares do Ensino Médio, os/as quais constituem nosso foco de atenção no presente trabalho. Dentre esses documentos, destacamos: a) os Parâmetros Curriculares Nacionais (PCN), elaborados e propostos pelo Ministério da Educação (MEC), em 1998, com o propósito de serem ricos instrumentos de apoio às discussões pedagógicas das escolas, à elaboração de projetos educativos, ao planejamento das aulas pelos professores e à reflexão sobre suas práticas educativas, e à análise do material didático; b) as Diretrizes Curriculares Nacionais Gerais para a Educação Básica (DCN) que visam orientar o planejamento curricular das instituições de ensino. Importante destacar que essas Diretrizes são normas obrigatórias, fixadas desde 1996 e revisadas em 2010 pelo Conselho Nacional de Educação $(\mathrm{CNE})^{3}$. Sendo obrigatórias, as DCN deveriam pautar as ações pedagógicas nas escolas. As temáticas de gênero e de sexualidade, no entanto, aparecem como transversais, motivo pelo qual - não raro - acabam sendo esquecidas e/ou pouco trabalhadas/exploradas. Acerca disso, Costa (2003, p.45) faz uma crítica ao fato de temáticas interessantes para crianças e jovens serem nomeadas e tratadas como transversais. Segundo ela, a maioria dos currículos continua priorizando as matérias que têm o objetivo de preparar o sujeito para um mundo ocidental coerente:

[...] uma evidência da necessidade de discutir outras questões na escola, temas novos, problemas novos. E como é que se resolveu isso? Já que não se pode romper com a ordem disciplinar, incluem-se temas transversais. Aquilo que deveria ser central é transversal. Aquilo que é problema da juventude hoje sexualidade, drogas, comunicação, sobrevivência, como viver neste mundo complexo? - se resolve nos temas transversais.

Com o surgimento de documentos tais como os que supracitamos, mesmo que ainda timidamente, a escola tem sido palco de situações e de aprendizagens relacionadas a temáticas que, até então, eram esporadicamente abordadas. No entanto, mesmo que há aproximadamente duas décadas os referidos documentos venham sendo pensados, elaborados e propostos, algumas temáticas neles mencionadas, como a sexualidade, quando efetivamente levadas para dentro da escola, ainda geram conflitos, resistências e estranhamentos, ora por parte de alunos/as, ora por parte de professores/as que não se sentem preparados/as para debater tais temas, ora por parte de

\footnotetext{
${ }^{3}$ As DCN tiveram origem na Lei de Diretrizes e Bases da Educação (LDB) de 1996 (Lei Federal 9.394/1996)
} 
familiares/responsáveis que não aceitam certas orientações oferecidas pela escola.

Em função das pesquisas que realizamos e de nossas atuações na Educação Básica, temos tido oportunidades de circular por algumas escolas e vivenciar alguns momentos de resistência, deparando-nos com situações que envolvem as questões de sexualidade e que merecem ser discutidas e problematizadas. Levando em conta esses aspectos, nosso principal propósito é, a partir da perspectiva teórica dos Estudos Culturais e dos Estudos de Gênero, de viés pós-estruturalista, analisar falas de jovens vinculados ao Ensino Médio sobre as questões de gênero e sexualidade a partir da apresentação de cenas veiculadas no Programa Pânico na Band. Antes, porém, descreveremos os aspectos metodológicos que possibilitaram a realização da investigação a partir da qual se originou esse artigo.

\section{ASPECTOS METODOLÓGICOS DA PESQUISA}

Estudos recentes, a saber: Tonon (2006), Pocahy e Nardi (2007), Louro (2008, 2009), Bento (2011), Goellner e Grespan (2011), sob a perspectiva dos Estudos Culturais e dos Estudos de Gênero, têm analisado as representações de homossexualidade que circulam em nossa sociedade ocidental, bem como as relações de poder estabelecidas entre as pessoas a partir dos sentidos a elas atribuídos.

Inspirado nessas abordagens, o presente artigo é um recorte de uma pesquisa de Mestrado cujo foco voltou-se às representações de gênero e sexualidade acionadas no programa televisivo Pânico na Band destinado, principalmente, ao público jovem. O texto que aqui apresentamos aborda as representações ligadas à homossexualidade, um dos eixos da pesquisa. Com o intuito de problematizar as formas como os/as jovens vêm percebendo tais representações, um grupo de estudantes pertencentes a uma escola pública de Ensino Médio e Técnico da região metropolitana de Porto Alegre foi convidado a participar dessa investigação ${ }^{4}$.

A participação dos/as estudantes se deu nos meses de novembro e dezembro de 2013, período em que esses/as jovens tinham idades entre 16 e 18

\footnotetext{
${ }^{4}$ Os cuidados éticos, no que diz respeito às investigações que envolvem seres humanos, foram tomados: a pesquisa foi aprovada pelo Comitê de Ética da Universidade, bem como todos os participantes assinaram um Termo de Consentimento Livre e Esclarecido. Aos menores de 18 anos também foi solicitada a autorização de seus responsáveis para a participação na pesquisa.
} 
anos e cursavam o terceiro ano do Ensino Médio noturno. Muitos residiam em bairros da cidade de Montenegro/RS, alguns no centro e outros em cidades vizinhas. Pouco mais da metade dos estudantes ou trabalhava durante o dia ou cursava um dos técnicos profissionalizantes na escola ou em outras instituições da cidade. A outra metade tinha os estudos como sua principal ocupação.

A turma era composta de aproximadamente 16 meninas e 14 meninos frequentes e, junto a eles/as, construímos nossa metodologia de pesquisa. Diante da impossibilidade da realização de um grupo focal com os/as estudantes daquela turma, por objeção deles/as mesmos/as, decidimos que ocorreriam quatro momentos de interação pesquisadoras/sujeitos da pesquisa, os quais ocupariam parte do tempo de cada aula de língua portuguesa dos meses de novembro e dezembro de 2013. Nesse ano, a escola possuía turmas em regime semestral, do currículo em extinção, e os/as alunos daquela turma tinham aulas de língua portuguesa durante o segundo semestre, todas as segundas-feiras. No primeiro momento, ocorrido no dia 11 de novembro de 2013, todas as informações a respeito da pesquisa foram expostas: a espontaneidade da participação, a desvinculação entre as atividades de pesquisa e a avaliação na disciplina, o sigilo, os cuidados éticos, as formas de registro das opiniões dos/as jovens. Eles/as receberam o Termo de Consentimento Livre e Esclarecido; os/as que já haviam completado dezoito anos e quiseram participar da pesquisa assinaram ali mesmo o Termo, outros/as, menores de idade, levaram-no para casa e trouxeram-no na semana seguinte. Houve outros três momentos para a realização das problematizações com os/as alunos/as, nos dias 18 e 25 de novembro de 2013 e 09 de dezembro de 2013, os quais denominamos encontros de discussão. Neles, os/as estudantes participaram oralmente das trocas de ideias a respeito de alguns quadros do programa televisivo Pânico na Band, cujos conteúdos tocavam as questões de gênero e sexualidade. O corpus desse artigo é, portanto, o conjunto de respostas dadas pelos/as jovens no encontro de discussão do dia 25 de novembro de 2013, em que foram problematizadas as representações de homossexualidade veiculadas em três quadros humorísticos. Abordaremos no presente texto, porém, as falas a respeito de dois desses quadros: As paródias do Bolinha e Poderoso Castiga - Sair do armário. As discussões foram gravadas em áudio e em áudio-vídeo (para os que assim desejaram), e alguns/algumas alunos/as quiseram também registrar a próprio punho suas opiniões. 


\section{DA HOMOSSEXUALIDADE À HOMOFOBIA: ATRIBUIÇÕES DE SIGNIFICADOS}

Para Louro (2009) no Ocidente, especialmente com a Revolução Burguesa e o Industrialismo, desencadearam-se processos políticos, econômicos, culturais e sociais bastante complexos - como uma nova divisão sexual do trabalho e a circulação de ideias feministas - responsáveis por reconfigurar as sociedades em variados aspectos. No que diz respeito à sexualidade, passou-se de um modelo de sexo único baseado no homem, para outro binário em relação ao gênero, em que o homem era central e estava em oposição à mulher. Também, essa noção avançou para um binarismo de sexualidade em que a heterossexualidade é o normal e a homossexualidade é o diferente. Sempre houve em todas as sociedades práticas sexuais e afetivas entre pessoas do mesmo sexo, entretanto, elas adquiriram novos sentidos com o passar dos anos. Para Louro (2009, p.87-88), não mais essas práticas seriam vistas como um pecado eventual, um erro ou uma falta a que qualquer um podia incorrer, suscetível à punição e talvez ao perdão. Passariam a ser entendidas como reveladoras de uma verdade oculta do sujeito, de um sujeito que precisaria ser punido, recuperado, recluso ou regenerado por meio da aplicação de práticas jurídicas, religiosas ou educativas.

Filho (2009, p.100) afirma que a homossexualidade foi uma prática sexual concomitante à heterossexualidade e à bissexualidade na história de diversos povos - ocorrendo, inclusive, a formação de um meio homossexual masculino nas grandes cidades ocidentais desde o século XVI, o que foi descrito por Schopenhauer e atestado em pesquisas da Antropologia e da História. Mesmo assim, a representação da homossexualidade marcada pelo olhar clínico, tal como se conhece hoje, apareceu somente nas sociedades ocidentais no século XIX. O autor cita o texto As sensações sexuais contrárias do médico alemão Carl Westphal, de 1870, no qual a homossexualidade foi tratada como desvio sexual e seus praticantes vistos como sujeitos dotados de algumas características físicas e psicológicas desviantes. Esse fato inaugurou uma série de investimentos de teóricos na procura das causas de tal anomalia.

De acordo com MacRae (2011, p.25-27), mostrar que os homossexuais "poderiam ser cidadãos tão bons, decentes e integrados quanto os heterossexuais" foi o objetivo dos defensores dos direitos dos homossexuais, no século passado, durante muito tempo. Inúmeras vezes, eles tentaram conquistar a simpatia da elite social, política e econômica de um país, protegendo suas reivindicações atrás de títulos médicos. Um exemplo dessa postura foram, em 1929, as impressões de seriedade e respeitabilidade acerca 
do Instituto de Ciência Natural - que era então uma espécie de quartel general do movimento homossexual - que o romancista inglês Christopher Isheerwood teve numa visita ao local, situado em um palácio em Berlim, onde atuava um dos mais importantes dos primeiros militantes gays, Magnus Hirschfeld. Entretanto, esse Instituto foi saqueado pelos nazistas em maio de 1933 e sua biblioteca de 10.000 exemplares foi incinerada junto ao busto de Hirschfeld. Com o advento do nazismo e do stalinismo encerrou-se a militância homossexual e somente a partir de 1948 ela foi retomada, por exemplo, com a criação, nos Estados Unidos, do Mattachine Society, que de início era uma organização semiclandestina, a qual objetivava integrar os homossexuais. Porém, conforme MacRae (op.cit.) os membros dessa organização aceitavam que a homossexualidade fosse caracterizada como uma doença e, com frequência, adotavam pseudônimos, uma posição talvez hoje julgada como tímida, mas compreensível considerando-se a repressão da sociedade estadunidense da época. O termo homossexual não era bem visto devido à ênfase no sentido sexual, utilizando-se em vez dele homófilo e homoerótico. Outros grupos semelhantes começaram a surgir em outros países, como: na França o Arcadie, na Dinamarca o Forbundet 48, na Holanda o COC (Associação pela Integração dos Homossexuais da Holanda), todavia, somente com os movimentos da década de 1960 em diversos países é que o movimento gay irá romper o modo de militância de até então e adquirir maior relevância.

Ainda conforme Filho (2009, p.100-101), referindo-se aos estudos de Mott $^{5}$, os termos homossexual e homossexualismo teriam aparecido, primeiramente em 1869, quando o escritor e advogado húngaro Karol Maria Kertbeny, sob o pseudônimo Dr. Benkert, os utilizou em seus artigos de jornais como forma de opor-se ao parágrafo 175 do Código Penal alemão que condenava os praticantes do amor do mesmo sexo à prisão com trabalhos forçados e de pleitear proteção a sua pessoa, bem como respeitabilidade à minoria discriminada. Desde então, a homossexualidade foi compreendida como doença, crime e pecado pela ciência e pela religião, principalmente pelo Cristianismo, o Islamismo e o Judaísmo. Em 1973, a Associação dos psiquiatras americanos retirou-a da lista de doenças mentais, sendo que até 1975 os homossexuais não eram aceitos como psicanalistas pelas respectivas sociedades. Em 1991 a Organização Mundial da Saúde retirou da lista de

${ }^{5}$ Antropólogo brasileiro, ativista em favor dos direitos civis LGBT e professor titular aposentado da Universidade Federal da Bahia. 
doenças a homossexualidade. Nos anos 1980, no Brasil, pelos esforços de Mott foram aprovadas diversas moções de associações científicas, em especial, da Sociedade Brasileira para o Progresso da Ciência e da Associação Brasileira de Antropologia. Além disso, importantes posições de crítica ao preconceito em torno da homossexualidade foram anunciadas.

Junqueira (2009, p.15) registra outras tentativas de combate ao preconceito contra homossexuais. Em 1998, na Inglaterra, foi instituído o Standards and Framework Act, uma responsabilização aos diretores de escolas a adotarem medidas de combate a qualquer forma de discriminação entre estudantes. Em 2007, aprovou-se o Equality Act a fim de combater "a discriminação por orientação sexual no acesso, no fornecimento e na utilização de bens e serviços públicos e privados", incluindo as escolas religiosas que "deverão ensinar o respeito à livre expressão sexual". No Brasil, foi lançado o Programa Brasil sem Homofobia, em 2004, em parceria com a sociedade civil organizada a fim de promover a cidadania e os direitos humanos de lésbicas, gays, bissexuais, travestis e transexuais (LGBT), por meio da defesa e equiparação de direitos civis e do combate à violência e à discriminação.

De acordo com algumas buscas por nós realizadas em sites ${ }^{6}$, o Programa Brasil sem Homofobia previa várias ações, dentre as quais: apoiar projetos de fortalecimento de instituições públicas e não governamentais que atuam na promoção da cidadania LGBT e/ou no combate à homofobia; capacitar profissionais e representantes do movimento LGBT que atuam na defesa de direitos humanos; disseminar informações sobre direitos, de promoção da autoestima LGBT; estimular a denúncia de violações dos direitos humanos da população LGTB. Entretanto, uma das primeiras iniciativas desse programa (a distribuição às escolas de um conjunto de materiais que ficou conhecido como Kit Escola Sem Homofobia) foi suspensa em 2011, pois sofreu duras críticas e fortes reações de setores conservadores atrelados ao Governo. No sítio da Secretaria de Direitos Humanos da Presidência da República há muitas informações a respeito dessas questões, dentre as quais destacamos o тепи LGBT, através do qual é possível conhecer os programas, os dados estatísticos e as leis vigentes, que dizem respeito a esse grupo, tanto no âmbito federal quanto nos âmbitos estaduais e municipais. No Rio Grande

${ }^{6}$ Dos sites: http://www.sdh.gov.br/assuntos/lgbt/legislacao;

http://oglobo.globo.com/brasil/governo-federal-recolhe-kit-educativo-anti-homofobia-7866048; http://www.brasil.gov.br/educacao/2011/05/haddad-nega-alteracao-em-conteudo-de-kit-escolarcontra-homofobia. Acesso em 23 de janeiro de 2015. 
do Sul, por exemplo, há leis que tratam dessas questões a partir de 2002, como o Decreto estadual $\mathrm{n}^{\circ} 48.117$ de 27 de junho de 2001, o qual instituiu o Dia 17 de maio, como Dia Estadual de Combate à Homofobia, em consonância com o Dia Internacional de Combate à Homofobia, data em que a Organização Mundial da Saúde retirou a homossexualidade do Código Internacional de doenças e com o Decreto federal de 04 de junho de 2010 que oficializou o dia 17 de maio como Dia Nacional de Combate à Homofobia.

Os pesquisadores Pocahy e Nardi (2007) tecem alguns esclarecimentos sobre o termo homofobia. Os autores destacam que esse termo traz alguns problemas em sua significação: o radical grego fobia confere um sentido psicológico ou inconsciente ao problema da discriminação, o que o restringiria a um âmbito individual, mascarando essa forma de violência. Entretanto, homofobia tem sido utilizado pelos movimentos GLBTTT (Gays, Lésbicas, Bissexuais, Travestis, Transexuais e Transgêneros) e queer a fim de expressar a aversão e o ódio aos homossexuais e a todas as demais manifestações que fogem do padrão de sexualidade heterossexual. Além disso, já há outra expressão que se descola do sentido psicologizante: heterossexismo, que não foi, porém, a opção dos autores em seu trabalho. Tal expressão demonstra diferentes formas de discriminação e violências contra prostitutas, transexuais, lésbicas e bissexuais: a putafobia, a transfobia, a lesbofobia, a homofobia e a bissexualfobia; vistas como expressões do ódio e não do medo psicológico. No presente artigo, o termo homofobia é utilizado no sentido dos movimentos LGBT e da perspectiva teórica que dá aporte ao trabalho, em consonância também com a definição adotada pela Secretaria de Direitos Humanos do Governo Federal em seu Relatório sobre a violência homofóbica no Brasil em 2012.

Podemos perceber que variados investimentos têm sido feitos a fim de garantir direitos a todos os cidadãos, principalmente àqueles por vezes considerados diferentes no que tange ao gênero e às sexualidades. Todavia, coexistem ações em sentido oposto, que buscam marcar a diferença e alimentar o preconceito, dentre as quais, a exibição de representações pejorativas sobre os sujeitos fora da norma heterossexual em artefatos da mídia. Portanto, esse artigo resulta de uma pesquisa que buscou pistas sobre o que significam - para alguns jovens do Ensino Médio - as representações de gênero e sexualidade exibidas pelo programa Pânico na Band. A mídia tem colaborado para criar e reproduzir representações diversas e, mais do que isso, tem atuado como uma pedagogia cultural, na medida em que ensina sobre os mais diversos temas. Alguns apontamentos teóricos sobre juventude fazem-se 
necessários a essa altura da presente abordagem para complementar a caracterização dos estudantes já trazida nos aspectos metodológicos da pesquisa.

Kehl (2007) pensa a juventude como sintoma da cultura, pelo viés da Psicologia, e afirma não ser fácil dizer com precisão o que é juventude, tendo em vista a elasticidade desse termo, de forma que, hoje, para ela "todos os adultos são jovens. A juventude é um estado de espírito, é um jeito de corpo, é um sinal de saúde e disposição. É um perfil de consumidor, uma fatia de mercado onde todos querem se incluir" [p. 89]. Mas nem sempre foi assim. A autora exemplifica que, no Brasil da década de 1920, rapazes de 25 anos já se vestiam como homens de 50, buscando traços de respeitabilidade e seriedade. Os homens e as mulheres eram muito mais valorizados quando chegavam à fase reprodutiva, do que enquanto em idades menores. Cabe-nos observar que, ainda hoje, em alguns contextos sociais brasileiros, ocorre a valorização dos sujeitos por sua capacidade reprodutiva e sexual. Há, por exemplo, meninas, que veem na maternidade uma forma de reconhecimento social. Portanto, a valorização da faixa etária que hoje chamamos juventude é recente. A autora esclarece que a origem do que hoje veio a chamar-se juventude coincide com a época da modernidade e da industrialização, momento em que se passou a chamar adolescentes aqueles/as na fase entre ser criança e ser adulto. Para a autora, adolescentes eram os sujeitos situados entre a maturidade sexual, a plena aquisição de capacidades físicas como força e coordenação, e o despreparo para o casamento e para o ingresso no mercado de trabalho.

Segundo Kehl (2007, p.92), o esticamento da condição de adolescentes - em que os jovens vivem mais tempo dependentes dos pais e alheios às responsabilidades da vida pública - tem ocorrido em países capitalistas devido ao progressivo aumento do tempo de escolarização dos jovens, à competitividade do mercado de trabalho e à escassez de empregos. Dos Estados Unidos, a partir da década de 1960, emerge a visão - que traz benefícios, mas contraditória - de adolescentes como fortes consumidores, a qual se difundiu no mundo capitalista, para o qual ser jovem tornou-se slogan, clichê publicitário e imperativo categórico, ou seja, uma condição para se pertencer a uma certa elite atualizada e vitoriosa.

A mesma autora destaca que os/as adolescentes pós-modernos/as têm sido afetados pela indústria cultural, independentemente das suas condições financeiras. Além disso, contam com liberdades muito próximas às dos/as adultos/as, mas poucas responsabilidades. Todos/as se identificam com uma 
imagem publicitária de juventude em que são expostos/as como jovens hedonistas, belos/as, livres, sensuais. Vende-se uma imagem de jovem consumidor/a que celebra a sensualidade adolescente, a busca de prazeres e novas sensações, o desfrute do corpo, a liberdade. Como se trata de uma cultura jovem, e não de uma idade biológica jovem, pessoas de várias faixas etárias têm se seduzido por ela, tentando permanecer e parecer o maior tempo possível jovem, como Kehl (2007, p.103) afirma "É que vivemos em uma cultura em que o espetáculo dita as normas de cidadania, organiza as relações sociais, estabelece valores, formata as identificações".

Ainda conforme a mesma autora, os/as adultos/as têm sofrido uma má consciência frente a esse imperativo de ser jovem e "há vagas de adultos sobrando" (KEHL, 2007, p.97-98), porque muitos destes passam a se comportar como teens; mães e pais dançam como os/as filhos/as, trocam confidências sobre drogas e sexo, posicionam-se a favor das transgressões deles/as junto a escolas e demais instituições. O que preocupa é que esse lugar do discurso de pais/mães que sabiam (ou pensavam que sabiam) como preparar seus/suas filhos/as não fica vazio, e vem sendo ocupado pelo discurso do mercado ditando as regras de vida aos/às jovens. Além disso, a realidade vem sendo mostrada de forma idealizada para a juventude, e pais/mães não conseguem oferecer-lhes outros valores, limites e parâmetros, que não os guiados pela lógica do consumo. A vida adolescente é representada pela publicidade, por exemplo, como algo sem limites, traduzido na potência do aparelho de som, na velocidade e resistência do automóvel e da moto, na curtição do álcool e do cigarro, no corpo aeróbico, esculpido em academias e objeto de desejo de crianças a idosos.

Sob um ponto de vista antropológico, Canevacci $(2005$, p.23) afirma que "escola, mídia e metrópole constituem três eixos que suportam a constituição moderna do jovem como categoria social", portanto a juventude surge num "terreno conflituoso, autônomo, inovador". Com o surgimento da escola, uma parcela da população passa a frequentá-la - os/as mais abastados/as. A mídia da década de 1950 produz novos modos e estilos de vida, sensibilidades, sexualidades. Já as cidades servem como cenário desses novos signos e desejos. O cinema retratara muitas das tensões da época relacionadas aos anseios daquela juventude emergente. Para o autor, antes da contemporaneidade, "os jovens não existiam como faixa etária [...] se transitava diretamente da adolescência [...] para o trabalho" (ibidem, p.22). Inicialmente, a ideia de juventude era para o aristocrata livre do trabalho ou para o/a filho/a do burguês educado para o trabalho, pois tanto o trabalho 
agrícola quanto, depois, o industrial faziam parte da vida dos/as filhos/as das classes populares.

Aliado a essas marcas, segundo Canevacci (2005, p.28) está um contexto de "culturas fragmentadas, híbridas e transculturais, consumo panoramático, comunicações mass-midiáticas", o qual contribui para uma "dilatação do conceito de jovem, virando do avesso as categorias que fixavam faixas etárias definidas e claras passagens geracionais", o que o autor denomina os jovens intermináveis. Tal denominação refere-se ao fato de que não é mais a idade que determina a juventude, mas sim o estado em que cada indivíduo se considera, de modo que cada um pode nunca acabar de ser jovem.

Feito esse delineamento conceitual a respeito de entendimentos centrais para esse trabalho, passamos - a seguir - a descrever alguns quadros do Programa Pânico na Band que deflagraram as discussões com os jovens participantes dessa investigação. Passamos, também, a empreender as análises do material produzido a partir dos encontros de discussão.

\section{AS PARÓDIAS DO BOLINHA ${ }^{7}$ DISSEMINANDO PRECONCEITOS}

Nessa primeira seção analítica serão discutidas algumas falas dos/as alunos/as produzidas a partir da exibição de algumas paródias do Bolinha exibidas no quadro Ixxxkenta, com Regina Ralé que é uma imitação do programa Esquenta ${ }^{8}$ da Rede Globo, com Regina Casé. Conforme pesquisa que fizemos na Internet, no site do programa Pânico na Band, no You tube e outros, houve onze paródias, veiculadas no Pânico nos meses de abril a junho de 2013. Durante os encontros de discussão problematizamos cinco paródias:

\section{A) ROBOCOP GAY ${ }^{9}$}

REGINA RALÉ - E com vocês: Bolinha!!! BOLINHA CANTA: Eu faço pose de macho Mas o meu pinto é minúsculo

Eu só tenho esses músculos

Pra não dar pinta de gay

Já fiz botox e plástica

Meu cavanhaque é ridículo

\footnotetext{
${ }^{7}$ Bolinha é o apelido de um dos integrantes do programa Pânico na Band: o Marcelo Picon. Nesses quadros, Bolinha é interpretado pelo humorista Márvio Lúcio dos Santos Lourenço.

${ }^{8}$ Mais informações no site http://gshow.globo.com/programas/esquenta/

Paródia da música Robocop Gay, do grupo Mamonas Assassinas. Do site http://cliquemusic.uol.com.br/artistas/ver/mamonas-assassinas. Acesso em 9 de agosto de 2014.
} 


\author{
Ainda sou argentino \\ E o pior não contei \\ A Ariadna ${ }^{10}$ é minha amante \\ E vem com um presente \\ Uma banana bem grande \\ Eu vou me apaixonar \\ Retoco a minha barba \\ Arranho o seu bigode \\ Na nuca também pode \\ Não dá pra disfarçar \\ Assumo que sou gay \\ Eu assumo que eu sou gay \\ E ontem mesmo eu dei \\ E ontem mesmo eu dei \\ Ah, eu dei, eu dei \\ E como eu gostei \\ Ah, eu dei, eu dei \\ E como eu gostei \\ Ai, como dói!
}

\title{
B) OLHA O GAY
}

REGINA RALÉ - o maior sucesso como cantor: Bolinha!!!

[estão de costas, o Bolinha olhando-se num espelho entre dois bailarinos de corpos sarados vestindo sungas e gravatas, estilo Gogo boys, todos rebolam quando inicia a música]

BOLINHA CANTA: Olha o gay!

Sendo gay!

Olha o gay!

Sendo gay!

Descobri que eu sou gay

Pro meu pai eu não contei

Ontem à noite eu mesmo dei

Pro Valmir

Pro Valmir do bar

A banana eu descasquei

Descasquei

No quiabo escorreguei

Escorreguei

E o bigode eu beijei

De quem? De quem?

Do Valdir

Do Valdir do Vasco

Olha o gay!

${ }^{10}$ Ariadna foi a primeira participante transexual do programa Big Brother Brasil.

Textura, v. 19 n.40, maio/ago.2017 
Sendo gay!

Bolinha!

C) VOU DE TÁXI ${ }^{11}$

REGINA RALÉ - Vamos ouvir e ver o cantor que está totalmente estourado, tanto no programa quanto por trás: Bolinha!!! [risos em geral e aplausos. Entra Bolinha conduzido pela mão por um bailarino com corpo sarado e vestido sensualmente]

BOLINHA CANTA: Pela janela do meu quarto

Oi, sou Bolinha! [uma voz masculina grita: Arrasou, querida!!]

Tô piscando

Quem será que vem me pegar?

O tamanho

Eu vou imaginar

Uma serpente

Que vem aqui me picar

No skype

Eu vi seu batom

Me deu medo

Porque é maior que o Rincon

Vem de táxi

Que eu pago

Eu to querendo

O seu nabo

Eu to querendo

(Na bu Na bu)

Vem meu homem.

\section{D) MARCHINHA DE CARNAVAL ALLAH-LA-Ô ${ }^{12}$}

REGINA RALÉ - Dia dos Namorados é que nem escola de samba do Rio de Janeiro, o Bolinha adora mesmo é ver a mangueira entrando!

BOLINHA CANTA: Dei pro Alaoooor

Me machucooou

Me machucou com um legume do Ceasa

A sauna estava quente

E queimou a minha raba

Sauna a vapoooor

Mas que calooor

${ }^{11}$ Paródia da música Vou de táxi de Angélica.

${ }^{12}$ Paródia da marchinha de carnaval Allah-la-ô de Haroldo Lobo e Nássara. 
Olha a cabeleira do Bolinha

Será que ele é? Será que ele é?

Bichinha!!!

Olha a cabeleira do Bolinha

Será que ele é? Será que ele é?

Bichinha!!!

Será que eu sou um boiola

Por que eu não gosto de mulher?

Muitos dizem que eu sou um viado

Porque curto Juliano Cazarré ${ }^{13}$

Corta pra minha 18 ! Bumbum! (4X)

[abaixa as calças e mostra as nádegas)

\section{E) URSINHO PIMPÃO ${ }^{14}$}

REGINA RALÉ - Gente, o próprio, cantor Bolinha, o boiola! BOLINHA CANTA: Vem meu bichinho querido

Meu companheirinho

Ursinho pintão

Eu te achei lá na Augusta

Quase na esquina da Consolação

Vem me fazer um carinho

Eu tenho um pintinho

Você um pintão

Vamos ao que interessa

Não faça com pressa

Abaixa o calção

Te pago em notas de cem

Vem meu brinquedinho

Ursinho pintão

Mama também

Pintão

Na televisão

Pintão

É tão bonita

A nossa relação

Sexual

Não vá meu bem

Pintão

Volta meu bem

Pintão

To bem tristinho

Sem meu pintão!

${ }^{13}$ Ator brasileiro, natural de Pelotas, RS. Do site: http://www.purepeople.com.br/famosos/julianocazarre p2657. Acesso em 28 de janeiro de 2015.

${ }^{14}$ Paródia da música Ursinho Pimpão, cantada por Balão Mágico, década de 1980. 
No início da exibição das cinco paródias aos estudantes, foi-lhes dito que pensassem, para depois responderem o que percebiam nas paródias. A seguir, transcrevemos algumas respostas dadas pelos/as jovens:

Piada, brincadeira com um integrante do programa. (Marli, 17 anos; Mônica, 17 anos; Lúcia, 16 anos; Joice, 18 anos; Róbson, 17 anos; Gustavo, 18 anos);

Nada de engraçado, só faz bullying com homossexuais. (Alex, 18 anos, Emanoel, 18 anos; Priscila, 17 anos);

Estão criticando os homossexuais, mostrando o que eles pensam sobre os homens gays. (Jéssica, 17 anos; Grasiele, 17 anos; Brenda, 17 anos);

Preconceito por parte do programa que faz piada com um dos integrantes. (Moisés, 17 anos; Rafael, 18 anos; Cristian, 18 anos);

Preconceituoso, pois expõe a opção sexual do humorista. (Tatiane, 17 anos; David, 17 anos; Luís, 17 anos)

Preconceito total, ridicularizando a opção sexual de cada pessoa, porém é algo que gera muito humor. (Taís, 18 anos);

Preconceito exalado, é só isso que fazem; julgar os outros. (Luciane, 16 anos);

Homofóbico. (Fernanda, 17 anos);

De uma forma ou de outra, eles influenciam a sociedade a ser preconceituosa. (Léo, 17 anos);

Preconceituosos mais uma vez. Isso influencia em vários aspectos negativos na sociedade. (Isadora, 17 anos).

Como é possível observar, seis estudantes - Marli (17 anos), Mônica (17 anos), Lúcia (16 anos), Joice (18 anos), Róbson (17 anos) e Gustavo (18 anos) - consideraram as paródias "piada, brincadeira com um dos integrantes". Para eles, parece ter se destacado uma representação humorística das homossexualidades, sem maiores desdobramentos, algo caricatural, teatral. Ressaltamos que o personagem Bolinha das paródias satiriza um dos integrantes ${ }^{15}$ do programa Pânico na Band cujo apelido é Bolinha. Ele é representado como um gay com certos trejeitos e atitudes cristalizadas e identificadas socialmente como típicas de um gay e, por isso, sujeito a inúmeras e intensas ofensas verbais. O programa mantém uma expectativa em torno da opção sexual pessoal desse integrante, promovendo, inclusive enquetes no site e durante várias das exibições aos domingos. Entendemos esse apelo ao humor como um uso perigoso da arte de divertir, uma

${ }^{15}$ Marcelo Picon de Santoz Gancho é produtor e apresentador de vários quadros do programa Pânico na Band. Do site: http://entretenimento.band.uol.com.br/paniconaband/videos/15126221/bolinha-responde-se-e-ounao-e-gay.html. Acesso em 28 de janeiro de 2015. 
autodepreciação consentida, visando prender a atenção do público e diverti-lo, como aponta Slavutsky ${ }^{16}(2014$, p. 38) ao afirmar que o humor pode ser utilizado de forma perigosa, inclusive autodepreciativa, para seduzir o público; o humor pode ser racista, preconceituoso, agressivo, irônico, sarcástico.

Em contrapartida, o preconceito foi destaque para catorze estudantes. Três alunos - Alex (18 anos), Emanoel (18 anos), Priscila (17 anos) afirmaram não haver "Nada de engraçado, só faz bullying com homossexuais". Para eles a questão do humor ficou em segundo plano, destacando-se o tratamento discriminatório para com os homossexuais. Três alunas - Jéssica (17 anos), Grasiele (17 anos) e Brenda (17 anos) - perceberam "crítica aos homossexuais, aos gays" e oito alunos - Moisés (17 anos), Rafael (18 anos), Cristian (18 anos), Tatiane (17 anos), David (17 anos), Luís (17 anos), Taís (18 anos), Luciane (16 anos) - afirmaram haver "Preconceito por parte do programa que faz piada com um dos integrantes". Somente a aluna Fernanda (17 anos) utilizou o termo homofóbico durante a discussão do quadro, o que aponta para a pouca ênfase que esse termo teve durante as aprendizagens desses estudantes. Para Junqueira $(2009$, p.17) existe uma pedagogia do insulto constante na vida escolar de jovens e adultos LGBT. Ela compõe-se de poderosos mecanismos de silenciamento e dominação, como piadas, brincadeiras e apelidos.

Consideramos que há muito a esclarecer no trabalho pedagógico dos/as professores/as junto aos/às alunos/as (e na qualificação dos docentes para isso) sobre o que é homofobia e de que formas ela se manifesta, especialmente, em situações que a dissimulam, como a de um programa televisivo humorístico. Conforme Pocahy e Nardi (2007) atos de homofobia ferem, mas seus efeitos ultrapassam a dor, eles demarcam posições sociais dos sujeitos, promovem a desumanização do outro, pelo uso de palavras, gestos e condutas ofensivas. É necessário que professoras e professores estejam aptos a identificar tais situações de violência na escola e a agirem da melhor forma possível.

Isadora (17 anos) e Léo (17 anos) perceberam que o quadro ensinou algo: "[...] eles influenciam a sociedade a ser preconceituosa", ou seja, ele atuou como uma pedagogia cultural, o que Sabat (2013) conceitua como uma pedagogia das imagens, as quais produzem formas de pensar e agir; valorizam certos comportamentos, estilos de vida e pessoas; consistindo em uma forma de regulação social produtora de padrões sociais.

\footnotetext{
${ }^{16}$ Abrão Slavutsky é psiquiatra e psicanalista gaúcho e estuda o humor.
} 
Evidencia-se, nas opiniões dos alunos, a diversificação de sentidos possíveis em relação a representações de gênero e sexualidade, uma vez que muitos e variados são os investimentos na educação sexual e de gênero desses jovens. Nas discussões sobre representações de gênero e sexualidade presentes nas paródias, o humor pareceu ter suavizado a violência contra os homossexuais para grande parte dos jovens, pois embora quatorze deles tenham se referido a preconceito, apenas uma jovem falou em homofobia. Tal fato aponta a necessidade de, cada vez mais, no âmbito escolar ser proporcionado espaço para práticas pedagógicas que tenham como foco de interesse a abordagem das questões de gênero e sexualidade.

Cabe referir também que a questão da heteronormatividade é a todo tempo acionada pelos quadros do Pânico na Band, pois com muita frequência as homossexualidades foram mostradas como vinculadas a uma postura desviante, que precisa ser corrigida. Para Bento (2011, p.550) "a bicha, o sapatão e o afeminado são essenciais para realimentar a heterossexualidade". Embora as falas de alguns alunos tenham salientado o preconceito e a discriminação articulados nos quadros do programa, as paródias foram entendidas muito mais como "brincadeiras" do que propriamente como ofensas verbais e prática homofóbica, revelando as relações de poder vigentes em nossa sociedade. Nas palavras de Slavutsky (2013, p.32) "A dimensão ética do humor se apoia na ousada irreverência. [...] o humor, às vezes, consegue driblar a censura, mas corre riscos. A ética do humor revela as entranhas do poder e de quem não tem poder, podendo gerar conforto e inquietação", ou seja, a homossexualidade aparece inferiorizada nas paródias em relação à heterossexualidade.

\section{PODEROSO CASTIGA EM SAIA dO ARMÁRIO! A TURMA DO MARCELO SEM DENTE}

Nessa seção problematizaremos as falas dos jovens produzidas a partir da apresentação do quadro $A$ turma do Marcelo sem dente do qual o personagem Poderoso Castiga participa. Esse personagem tem como característica principal a prática de exorcismo, expulsando demônios, inclusive de objetos, no caso, de um armário. É uma espécie de paródia de pastores de Igrejas Evangélicas Neopentecostais. O referido episódio havia sido exibido pelo programa Pânico na Band no dia 4 de agosto de 2013 e foi apresentado 
aos alunos no encontro de discussão ocorrido no dia 25 de novembro de 2013. Segue a transcrição do quadro:

PODEROSO CASTIGA - Atenção! Se tiver algum demônio aqui dentro, que saia desse armário dessa senhora!!!

IMITADOR DO MIGUEL FALABELA - Cala a boca, Magda!

PODEROSO CASTIGA - Ah, saiu o Miguel!! (risos) tem mais demônio aí? Se tiver mais um demônio, saia!

IMITADOR DO JÔ SOARES - Uau!! Barbílio, vem comigo? PODEROSO CASTIGA - (risos) Ele mandou o Eduardinho! (risos) Sem nenhum demônio, o armário agora está tranquilo, você vai poder usar. $\mathrm{O}$ armário não tá se mexendo mais! (gestos e movimentação de espanto) Opa! Opa! Opa! Tá balançando!

MULHER - Quem procura acha!

PODEROSO CASTIGA - Arreia, arreia!!! Vaza! Arreia! Vá! Sai demônio! Saiu? Tem algum demônio aí dentro? Satanás, saia do armário desta mulher! Saia do armário, demônio! Vai sair? (Voz de dentro do armário apenas urra a cada pergunta do Poderoso Castiga)

PODEROSO CASTIGA - Vai sair? Vai sair? Por quê? Vai sair? Satanás? Ou é um poodle ou é um schnauzer! Bota bombinha, aquela bombinha pra caralho! (solta uma bombinha dentro do armário)

PODEROSO CASTIGA - Não aconteceu porra nenhuma! Vou colocar duas. Vou colocar aqui nesse PVC, óóóó. Voou PVC da câmera! Essa aqui é a bombinha de um que eu estourei, agora vou estourar essa aqui que é de cinco. Ai, caralho!! Agora não tem como satanás não sair, porque agora eu vou soltar três bombinhas de cinco, que dá quinze.

BOLINHA - (sai de dentro do armário) Não, quinze não, não!!! Quinze não!! (risos)

PODEROSO CASTIGA - Péra aí, Bolinha! Agora saiu, arregou! Não tem mais ninguém no armário da moça, você pode levar pra casa, qualquer problema fala comigo no twitter [...]

Algumas considerações dos alunos acerca do quadro foram: 
Piada com religião, envolvendo Deus, muito ridículo. (Priscila, 17 anos; Taís, 18 anos; Cristian, 18 anos; Brenda, 17 anos);

Desnecessário, sem graça, não acrescenta nada de conhecimento. (Alex, 18 anos; David, 17 anos; Lúcia, 16 anos; Gustavo, 18 anos; Moisés, 17 anos; Jéssica, 17 anos);

Ironiza a expressão "sair do armário". (Luís, 17 anos);

Fizeram com que os apresentadores saiam do armário e assumam o que eles são. (Mônica, 17 anos);

Deboche de pessoas famosas, como o Jô soares, insinuando que ele é gay, mas não saiu do armário ainda. (Róbson, 17 anos, Rafael, 18 anos);

Deboche e mau gosto com o homossexualismo. (Isadora, 17 anos);

Eles não pensam que crianças podem ver isso. Não estão nem um pouco preocupados. (Grasiele, 17 anos).

Três alunas Priscila (17 anos), Taís (18 anos), Brenda (17 anos) e um aluno Cristian (18 anos) chamaram a atenção para o aspecto religioso que foi tratado como piada. Foi recorrente a percepção dos alunos acerca da mistura entre aspecto religioso e humor. Por se tratar de um quadro humorístico, é possível a expressão de certos enunciados não adequados para muitas ocasiões, incluindo os considerados tabus como Slavutzky (2014, p. 86) afirma: "um dos segredos do humor é que ele pode se aproximar do tabu. O tabu é proibido, algo que se deve evitar, ou ser tratado com cautela [...]", portanto a paródia tem no humor certo escape para não ser considerada ofensa. Slavutzky (2014, p.34) afirma também que o humor permite uma "visão que escarnece até do sagrado, que mobiliza o amor, o ódio, o erotismo e a agressividade. Proporciona prazer a uns e aflige a outros na sua crítica". Esses quatro alunos terem assinalado o aspecto religioso como um dos mais importantes percebidos por eles no quadro evidencia um dos atravessamentos que compõem a atribuição de sentidos pelos sujeitos contemporâneos: a religião. No caso, desrespeitar a religião e Deus parece ter sido mais grave do que ofender pessoas homossexuais, o que explicita as relações de poder e a hierarquia vigentes na sociedade.

Seis jovens _ Alex (18 anos), David (17 anos), Gustavo (18 anos), Moisés (17 anos), Lúcia (16 anos) e Jéssica (17 anos) _ avaliaram o quadro humorístico como "Desnecessário, sem graça", sem apontarem nenhum outro aspecto relevante. Entretanto, demonstraram, gestualmente, concordar com os três colegas: Róbson (17 anos), Rafael (18 anos) e Luís (17 anos) e com as três colegas: Mônica (17 anos), Isadora (17 anos) e Grasiele (17 anos), que apontaram "deboche com os homossexuais, ironia com a expressão 'sair do armário’ e mau exemplo para as crianças”. 
De acordo com MacRae $\left(2011\right.$, p.26) e sites que pesquisamos ${ }^{17}$, a expressão sair do armário é uma metáfora que passou a estar associada ao universo gay desde o episódio de Stonewall e significa assumir publicamente a homossexualidade. No final da década de 1960, na esteira das manifestações da contracultura, do surgimento do movimento hippie, do maio de $1968 \mathrm{em}$ Paris, da luta pelos direitos civis dos negros e do feminismo; em 28 de junho de 1969, em Nova Iorque, um grupo de homossexuais que frequentava o bar Stonewall, no bairro Greenwitch Village, insatisfeito com os abusos e repreensões de autoridades locais, revoltou-se contra uma blitz policial e deu início a uma série de conflitos violentos que prolongou-se por três noites. No ano seguinte, em 1970, surgiu o Gay Liberation Front, nos Estados Unidos, considerada a primeira parada gay da história, ocasião em que milhares de pessoas marcharam em São Francisco, Los Angeles e Nova Iorque, celebrando o primeiro aniversário da batalha de Stonewall. A data marca o Dia Mundial do Orgulho Gay.

Alguns dos estudantes perceberam deboche e ironia no uso da expressão sair do armário. De fato, o seu uso pelo personagem Poderoso Castiga visa ofender e ridicularizar, tendo em vista a associação ao termo demônio ser uma forma de representar a homossexualidade como mal a ser exorcizado pela religião, uma reiteração do sentido de homossexualidade pecadora. Conforme a pesquisadora Sedgwick (2007, p.8) “'O armário' e 'a saída do armário', ou 'assumir-se', [...] têm sido as mais magnéticas e ameaçadoras dessas figuras. O armário é a estrutura definidora da opressão gay no século XX." A saída do armário tem circulado em nossa sociedade como uma ameaça à heterossexualidade masculina, principalmente, por isso, ela tem aparecido constantemente em variadas situações. A propósito, gostaríamos de citar que em outro quadro problematizado com os jovens durante a pesquisa _ A escolinha do professor Feliciano _, porém não abordado nesse artigo, a última fala do professor Feliciano foi "E se eu sair do armário, óóó!!!” acompanhada de alguns gestos obscenos com um cacetete que segurava em suas mãos. Ali, a figura do professor Feliciano cumpria uma representação binária de sexualidade: $\mathrm{o}$ confronto heterossexualidade $\mathrm{X}$ homossexualidade, pois ele encarnava a norma heterossexual junto aos alunos

${ }^{17}$ Informações nos sites http://www.brasil.gov.br/cidadania-e-justica/2014/07/sabado-28-foi-o-diainternacional-do-orgulho-lgbt e http://oglobo.globo.com/mundo/o-movimento-gay-no-mundo-emfotos-532964. Acesso em 2 de fevereiro de 2015. 
ao se vestir como homem e tentar ensinar seus discentes a se tornarem 'homens de verdade', mas ao mesmo tempo, não podia deixar vir a público qualquer manifestação vista como homossexual, por isso sua fala e gestos ao final do quadro foram no sentido de manter privado seu segredo para não ser punido. Ainda de acordo com Sedgwick (2007, p.3):

O armário gay não é uma característica apenas das vidas de pessoas gays. Mas, para muitas delas, ainda é a característica fundamental da vida social, e há poucas pessoas gays, por mais corajosas e sinceras que sejam de hábito, por mais afortunadas pelo apoio de suas comunidades imediatas, em cujas vidas o armário não seja ainda uma presença formadora.

Outro aspecto apontado pela autora é que a atitude de assumir-se está distante de ser um marco de reconhecimento de direitos e respeito, de forma que os acontecimentos após Stonewall, embora tenham servido para muitas pessoas de impulso e promessa da autorrevelação gay, ainda não foram capazes de alterar significativamente o reino do sagrado, pois Sedgwick (2007, p.9) assinala que "Para as antenas finas da atenção pública, o frescor de cada drama de revelação gay (especialmente involuntária) parece algo ainda mais acentuado em surpresa e prazer, ao invés de envelhecido".

Para Junqueira (2012, p.286, grifos do autor) a "pedagogia do armário interpela a todos/as". O armário seria mais do que um processo de regulação para pessoas manterem em segredo e em silêncio seu distanciamento em relação à norma heterossexual. Ele atua como "um regime de controle de todo $o$ dispositivo da sexualidade", que valoriza aqueles que se conformam aos valores e às instituições heteronormativas, o que produz "uma gestão das fronteiras da (hetero)normalidade (na qual estamos todos/as envolvidos/as e pela qual somos afetados/as)". Portanto, vemos que situações como as de humor presentes no quadro debatido tanto agem junto às homossexualidades no sentido de ofendê-las, rebaixá-las, incriminá-las etc, quanto junto à heterossexualidade dizendo algo do tipo "Não seja um daqueles se não quiser ser tratado daquela maneira". Seguindo esse raciocínio, cabe o que Junqueira (2012, p.286) afirma sobre a pedagogia do armário: compõe-se de "dispositivos e práticas curriculares de controle, silenciamento, invisibilização, ocultação e não-nomeação", os quais operam sob a lógica da heteronormatividade e promovem a "(des)legitimação de corpos, saberes, práticas e identidades". Para o autor, a escola _ que é um local do conhecimento _ tem se mantido em relação à sexualidade e ao gênero como lugar de censura, desconhecimento, ignorância, violência, medo e vergonha. 
É possível afirmar que a escola tem sido ainda local de conhecimentos também predominantemente heteronormativos; basta olharmos atentamente para as representações de gênero, sexualidade e família presentes nos livros didáticos distribuídos pelo Ministério da Educação para a Educação Básica ou lermos estudos acadêmicos sobre esses temas. Também há grandes dificuldades junto a comunidades escolares (pais, professores, gestores) de inserir com qualidade conhecimentos que perturbam a heteronormatividade. Um exemplo disso foi a (já citada nesse texto) proibição da distribuição do Kit homofobia para as escolas por pressões de setores conservadores do governo federal. Com base em nossas experiências como docentes, percebemos que, em algumas escolas, trabalhar as questões de sexualidade e gênero é considerada uma tarefa difícil por parte do grupo de professores, tendo em vista as reações dos alunos, pois muitos acabam levando para o lado pessoal alguma colocação que colegas fazem e geram-se desentendimentos e brigas) e tendo em vista também as interpretações de pais e responsáveis sobre o que souberam a respeito de trabalhos sobre essas temáticas em sala de aula, especialmente famílias que seguem religiões mais conservadoras. Tem sido difícil para a própria instituição escolar sair do armário no sentido de assumir seu papel como difusora e problematizadora de conhecimentos - no plural. Para Junqueira (2009, p.36):

Mesmo com todas as dificuldades, a escola é um espaço no interior do qual e a partir do qual podem ser construídos novos padrões de aprendizado, convivência, produção e transmissão de conhecimento, sobretudo se forem ali subvertidos ou abalados valores, crenças, representações e práticas associados a preconceitos, discriminações e violências de ordem racista, sexista, misógina e homofóbica.

Indo ao encontro do exposto, percebemos que a respeito do quadro humorístico discutido _ A turma do Marcelo sem dente _ nenhum dos (as) estudantes mencionou se tratarem de situações homofóbicas, o que nos parece indicar a pouca problematização na escola e em meios de comunicação a respeito do que é homofobia e do respeito aos direitos humanos. Junqueira (2012, p.282, grifos do autor) define

a homofobia como um fenômeno social relacionado a preconceitos, discriminação e violência voltados contra quaisquer sujeitos, expressões e estilos de vida que indiquem 
No Brasil, a homofobia ainda não foi tipificada como crime. Em janeiro de 2015, o projeto de lei 122/2006, que previa criminalizar a homofobia e tramitava no Senado há oito anos foi arquivado. Em maio, a deputada Maria do Rosário (PT/RS) criou o projeto de lei 7582/2014 - que tipifica crimes de ódio, preconceito e intolerância contra diferentes grupos está em tramitação na Comissão de Constituição e Justiça (CCJ) da Câmara ${ }^{18}$.

\section{CONSIDERAÇÕES FINAIS}

É importante dizer que a pesquisa de Mestrado, da qual se originou esse artigo, delineou-se a partir de uma necessidade que os alunos tinham em discutir questões de gênero e sexualidade em sala de aula, já que nas segundasfeiras, dia da semana após a exibição do Pânico na Band, comentários, críticas e diálogos eram tecidos sobre o que haviam assistido no domingo. A produção de dados foi importante para a investigação em si, mas as discussões foram também muito relevantes para os alunos que puderam, através da pesquisa, saber e discutir um pouco mais sobre questões que têm sido palco de discussões em distintos espaços: governamentais, educacionais e midiáticos. E aqui damos destaque às homossexualidades que têm saído dos espaços de silêncios e proibições e ganhado força como uma possibilidade, dentre tantas outras, de se viver e desfrutar a sexualidade.

Nesse sentido, ancoradas nas argumentações de Costa (2003) trazidas no início desse artigo, consideramos que as escolas precisam dar conta de uma gama de temáticas que vai além de um currículo cuja centralidade volta-se, quase que exclusivamente, às disciplinas tradicionais. $\mathrm{O}$ modo como essas temáticas têm sido nomeadas e, consequentemente, trabalhadas na educação básica ainda não tem conseguido subverter naturalizações acerca da sexualidade, nem as representações preconceituosas a respeito de quem foge à norma sexual imposta pela sociedade ocidental. Portanto, afirmamos que a transversalidade dada à educação de gênero e sexual não tem dado conta de uma formação dos jovens com vistas à valorização das múltiplas identidades, ao reconhecimento das diferenças, ao respeito à diversidade, à garantia dos direitos humanos. São muitas as instâncias operando predominantemente para

\footnotetext{
18 Dos sites: http://www.redebrasilatual.com.br/cidadania/2015/05/homofobia-novo-projeto-de-leiretoma-mobilizacao-no-congresso-926.html

http://www25.senado.leg.br/web/atividade/materias/-/materia/79604
} 
a manutenção da norma heterossexual e seus processos de exclusão, ao passo que são escassas as iniciativas de docentes, instituições de ensino, mídia, setores da administração pública, iniciativa privada, dentre tantos, para o debate e enfrentamento dessas questões.

É necessário que haja, por parte das Secretarias de Educação em parceria com outros setores (Assistência Social, Secretaria de Saúde, Poder Judiciário, órgãos de polícia, Universidades), um planejamento de ações conjuntas e frequentes de educação para a equidade de gênero e sexual, não só nas escolas, mas em outros locais de atendimento à população.

Entretanto, enquanto tais ações não ocorrem, é importante que algumas fissuras sejam feitas já pelos (as) professores (as), os (as) quais devem ser orientados (as) por meio de atualizações _cursos, palestras, grupos de estudos, reuniões pedagógicas _ quanto à necessidade de tratarmos desses temas e trabalharmos para subverter a norma.

É preciso ampliar o currículo da escola, pois a educação formal ancorada nas disciplinas e na escassa abordagem dos temas transversais - é apenas uma das modalidades de educação existentes hoje. Costa (2003) destaca que é tarefa do/a professor/a oportunizar, na escola, a discussão sobre o que a televisão ensina. Para a autora, a televisão opera inúmeras pedagogias culturais, ou seja, a televisão também educa, e nas mais variadas direções.

Em nossa pesquisa, foi possível trabalhar em sala de aula com materiais que não são considerados didáticos, mas se revelam altamente produtivos para educar. Essa foi a experiência de uma de nós, como professora de língua portuguesa de uma turma de terceiro ano do Ensino Médio público. Nas aulas de segunda-feira à noite, o programa televisivo Pânico na Band, exibido aos domingos à noite, invadia a sala de aula informalmente até que se tornou pauta de discussões. O resultado disso foi uma rica troca de experiências entre os/as estudantes e pesquisadora, além da certeza de que há muito a se fazer para desnaturalizar verdades que têm causado preconceito e violência àqueles que escapam à heteronormatividade.

\section{REFERÊNCIAS}

BRASIL, Secretaria de Direitos Humanos da Presidência da República. Relatório sobre a violência homofóbica no Brasil em 2012. Disponível em: http://www.sdh.gov.br/assuntos/lgbt/pdf/relatorio-violencia-homofobica-ano2012. Acesso em 20 de outubro de 2014. 
BENTO, Berenice. Na escola se aprende que a diferença faz a diferença. Estudos Feministas, Florianópolis, vol. 19, p.548-559, maio-ago/2011.

CANEVACCI, Máximo. Culturas extremas. Mutações juvenis nos corpos das metrópoles. Trad. Alba Olmi. Rio de Janeiro: DP\&A, 2005.

COSTA, Marisa. Quem são? Que querem? Que fazer com eles? Eis que chegam às nossas escolas as crianças e os jovens do século XXI. In: MOREIRA, Antônio; ALVES, Maria P.; GARCIA, Regina (Orgs.). Currículo, cotidiano, e tecnologias. Araraquara: Junqueira \& Marin, 2006. p. 93-110

A escola tem futuro? A escola com que sonhamos é aquela que assegura a todos a formação cultural e científica para a vida pessoal, profissional e cidadã. Entrevista com José Libâneo. Rio de Janeiro: DP\&A, 2003. p. 23-52.

GREEN, Bill e BIGUM, Chris. Alienígenas na sala de aula. In: SILVA, Tomaz Tadeu. Alienígenas na sala de aula: uma introdução aos estudos culturais em sala de aula. 8 ed. RJ:Vozes, 2009. p.208-248.

GRESPAN, Carla Lisbôa; GOELLNER, Silvana Vilodre."Querem, na escola, transformar seu filho de 6 a 8 anos em homossexual": Sexualidade, educação e a potência do discurso heteronormativo. Revista entreideias, Salvador, n.19, p.103-122, jan./jun. 2011.

FILHO, Alípio de S. Teorias sobre a Gênese da Homossexualidade: ideologia, preconceito e fraude. In: Diversidade Sexual na Educação: problematizações sobre a homofobia nas escolas. JUNQUEIRA, Rogério (org.). Brasília: Ministério da Educação, Secretaria de Educação Continuada, Alfabetização e Diversidade, UNESCO, 2009. p.95-124.

HALL, Stuart. A centralidade da cultura: notas sobre as revoluções culturais do nosso tempo. Educação \& Realidade, v. 22, n.2, jul./dez., 1997.

JUNQUEIRA, Rogério. Pedagogia do armário e currículo em ação: heteronormatividade, heterossexismo e homofobia no cotidiano escolar. In: MISKOLCI, Richard; PELÚCIO, Larissa (Orgs.). Discursos fora da ordem: sexualidades, saberes e direitos. São Paulo: Annablume; Fapesp, 2012. p.277305.

(org.). Diversidade Sexual na Educação: problematizações sobre a homofobia nas escolas. Brasília: Ministério da Educação, Secretaria de Educação Continuada, Alfabetização e Diversidade, UNESCO, 2009. 
KEHL, Maria Rita. A juventude como sintoma da cultura. In: NOVAES, Regina; VANNUCHI, Paulo (orgs). Juventude e sociedade: Trabalho, educação, cultura e participação. São Paulo: Perseu Abramo e Instituto Cidadania, 2007. p.89-114.

LOURO, Guacira. Heteronormatividade e Homofobia. In: Diversidade Sexual na Educação: problematizações sobre a homofobia nas escolas. JUNQUEIRA, Rogério (org.). Brasília: Ministério da Educação, Secretaria de Educação Continuada, Alfabetização e Diversidade, UNESCO, 2009. p. 85-94.

Cinema e sexualidade. Educação e Realidade. Porto Alegre, vol.33 (1), $\overline{\mathrm{jan}} / \mathrm{jun}$ 2008, p. 81-98.

MACRAE, Edward. Os respeitáveis militantes e as bichas loucas. In: Stonewall $40+o$ que no Brasil? COLLING, Leandro (org.). Salvador: EDUFBA, 2011. p. 21-36.

POCAHY, Fernando e NARDI, Henrique. Saindo do armário e entrando em cena: juventudes, sexualidades e vulnerabilidade social. Estudos Feministas. Florianópolis, vol. 15, p. 45-66, Jan. 2007.

SABAT, Ruth. Gênero e sexualidade para consumo. In: LOURO, Guacira; FELIPE, Jane; GOELLNER. Corpo, gênero e sexualidade. Petrópolis, RJ: Vozes, 2013. P.149-159.

SEDGWICK, Eve Kosofsky. A epistemologia do armário. Cadernos Pagu. jan-jun/ 2007:19-54. Tradução: Plínio Dentzien; Revisão: Richard Miskolci e Júlio Assis Simões. Epistemology of the Closet. In: ABELOVE, Henry et alli. The lesbian and gay studies reader. New York/London, Routledge, 1993. p.45-61.

SLAVUTSKY, Abraão. Humor é coisa séria. Porto Alegre: Arquipélago Editorial, 2014.

TONON, Joseana B. Recepção de telenovelas: identidade e representação da homossexualidade. Um estudo de caso da novela "Mulheres Apaixonadas". Comunicação e Informação, vol. 9, n.1; p. 30-41; jan/jun. 2006.

Recebido em 06/07/2016

Aprovado em 12/12/2016 
Textura, v. 19 n.40, maio/ago.2017 